\title{
Centro de parto normal e \\ assistência obstétrica centrada \\ nas necessidades da parturiente*
}

DELIVERY CENTER AND OBSTETRIC ASSISTANCE FOCUSED ON THE PARTURIENT'S NEEDS

CENTRO DE PARTO NORMAL Y LAASISTENCIA OBSTÉTRICA CENTRADA

EN LAS NECESIDADES DE LA PARTURIENTA

\author{
Nilce Xavier de Souza Machado', Neide de Souza Praça²
}

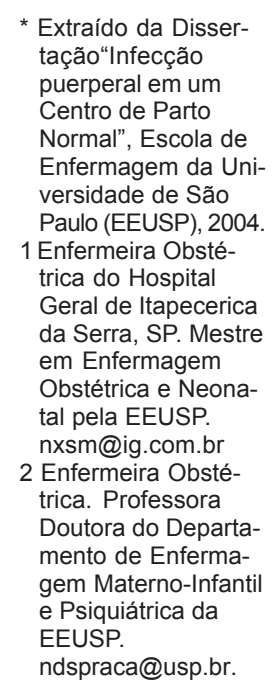

RESUMO

Levando em conta os vários estudos e reflexões a respeito do novo modelo de assistência ao parto e nascimento (assistência humanizada), e trabalhando como enfermeira obstétrica em um Centro de Parto Normal, surgiu o questionamento a respeito desse conceito, devido às diversas conotações dadas a esse termo. Este artigo foi produzido com a finalidade de divulgar nossa proposta de substituição da expressão "assistência humanizada ao parto", por "assistência obstétrica centrada nas necessidades da parturiente", e de discorrer como essa assistência é prestada no Centro de Parto Normal do Hospital Geral de Itapecerica da Serra (SP), que segue um protocolo de condutas obstétricas e normas preconizadas pelo Ministério da Saúde.

\section{DESCRITORES}

Humanização do parto.

Enfermagem obstétrica.

Assistência centrada no paciente.

\section{ABSTRACT}

As an obstetric nurse working in a Delivery Center and considering the studies and reflections on the new model of assistance to labor and birth (humanized assistance), I started to think about this concept, given the various connotations attributed to the term. This article was written with the aim of divulging our proposal of replacement of the expression "humanized assistance to childbirth" for "obstetric assistance focused on the parturient's needs", and to describe the assistance given at the Delivery Center of the General Hospital of Itapecerica da Serra, in the São Paulo Metropolitan Region, where a protocol of obstetric behavior and rules recommended by the Ministry of Health is followed.

\section{KEY WORDS}

Humanizing delivery.

Obstetrical nursing.

Patient-centered care.

\section{RESUMEN}

Teniendo en cuenta los variados estudios y reflexiones respecto al nuevo modelo de asistencia del parto y nacimiento (asistencia humanizada), y trabajando como enfermera obstétrica en un Centro de Parto Normal, surgió el cuestionamiento relacionado a ese concepto, debido a las diversas connotaciones que se le ha dado. Este artículo fue producido con la finalidad de divulgar nuestra propuesta de sustitución de la expresión "asistencia humanizada del parto", por "asistencia obstétrica centrada en las necesidades de la parturienta", y de discurrir cómo esa asistencia se presta en el Centro de Parto Normal del Hospital General de Itapecerica da Serra (SP), que sigue un protocolo de conductas obstétricas y normas preconizadas por el Ministerio de Salud.

\section{DESCRIPTORES}

Humanización del parto.

Enfermería obstétrica.

Atención dirigida al paciente. 


\section{INTRODUÇÃO}

Desde meados da década passada, vem se disseminando pelo país um modelo de assistência obstétrica, recomendado pela Organização Mundial da Saúde (OMS), que realça a mudança no olhar do profissional de saúde sobre a parturiente e sua família. Trata-se dos Centros de Parto Normal.

Os Centros de Parto Normal atendem as normas preconizadas pelo Ministério da Saúde ${ }^{(1)}$, conforme Portaria 985/99 GM. Constituem-se em unidades de atendimento ao parto normal, localizadas fora do centro cirúrgico obstétrico. Dispõem de um conjunto de elementos destinados a receber a parturiente e seus acompanhantes, permitindo um trabalho de parto ativo e participativo, empregando práticas baseadas em evidências recomendadas e que os diferenciam dos serviços tradicionais de atenção obstétrica. As primeiras recomendações para esta modalidade de assistência foram citadas pela Organização Mundial da Saúde, em 1996(2).

Vale destacar que os Centros de Parto Normal surgiram com o objetivo de resgatar o direito à privacidade e à dignidade da mulher ao dar à luz num local semelhante ao seu ambiente familiar, e ao mesmo tempo garantir segurança à mãe e seu filho, oferecendo-lhes recursos tecnológicos apropriados em casos de eventual necessidade. Seguem um padrão de procedimentos previamente estabelecidos e que direcionam as ações que realizam.

O estímulo à implantação deste modelo de assistência, no país, ganhou força, a partir da década de oitenta, quando o movimento de mulheres, no Brasil e no mundo, passou a questionar as práticas obstétricas de rotina e apresentar propostas para humanizar o atendimento ${ }^{(3)}$. Nesse período disseminou-se a divulgação de que na maioria dos países desenvolvidos a assistência ao parto e nascimento de baixo risco fundamenta-se na atenção prestada por enfermeiras obstétricas e por parteiras especializadas, cuja formação está voltada para o suporte emocional e o atendimento da mulher e do recém-nascido, sem interferir no processo fisiológico do parto, permitindo à mãe vivenciar esse momento de forma prazerosa e segura. Este modelo de assistência prevê que, durante a gestação, a mulher tem a oportunidade de estabelecer o plano de assistência ao parto, junto com o profissional que a atende, e seu primeiro contato, como parturiente, se dá na primeira relação com os profissionais não médicos, garantindo-se, contudo, o acesso a níveis de assistência de maior complexidade.

Este movimento de mudança na assistência obstétrica envolve, também, legitimidade profissional e corporativa, com um redimensionamento dos papéis e poderes na cena do parto, com o deslocamento da função principal no parto normal, do médico obstetra para a enfermeira obstétrica (procedimento legitimado pelo Ministério da Saúde), e do centro cirúrgico (palco da ação) para a sala de parto ou casa/centro de parto $^{(4)}$.

No espaço hospitalar, existe uma série de obstáculos para se implantar uma metodologia de assistência que promova o parto normal. A equipe de saúde não aceita com tranqüilidade a mobilidade da mulher, e ela própria sente-se pouco à vontade para decidir sobre os procedimentos de seu parto. Sobrepondo-se a essa situação, os Centros de Parto Normal tornam menos hierarquizadas as relações entre as parturientes e os prestadores de cuidados, e oferecem um ambiente onde a mulher sente-se mais à vontade diante dos eventos que a circundam ${ }^{(5)}$.

O Ministério da Saúde ${ }^{(1)}$, exercendo seu papel normatizador, implantou um conjunto de ações por meio de Portarias Ministeriais com o objetivo de estimular a melhoria da assistência obstétrica e de regulamentar a atuação do enfermeiro obstetra na realização do parto normal sem distocia, aplicando práticas baseadas em evidências.

Essas considerações nos mostram a estreita relação entre os Centros de Parto Normal e a assistência obstétrica baseada em evidências, ambos tendo a enfermeira obstétrica como principal aliada e implementadora.

Considerando essa situação e levando em conta os vários estudos e reflexões a respeito do novo modelo de assistência obstétrica ao parto e nascimento - assistência humanizada em Centro de Parto Normal - julgamos que a expressão assistência humanizada não reflete a abrangência da assistência prestada nesses serviços de assistência ao parto e nascimento, o que originou nosso questionamento a respeito desse conceito. Acresce-se o desgaste do termo pelas diversas conotações a ele atribuídas.

Nossa trajetória profissional, como enfermeira obstétrica, com atuação em diversos serviços de obstetrícia, que seguiam o modelo tradicional de assistência ao parto foi enriquecida pelo trabalho atual no Centro de Parto Normal de Itapecerica da Serra, SP, inserido em uma instituição que tem como objetivo a redução do número de cesarianas e o incentivo ao parto normal. Nele é adotada a tecnologia apropriada ao parto e nascimento com estímulo à assistência que valoriza as necessidades da parturiente.

Essa experiência, agregada à vivência profissional anterior, motivou-nos a refletir sobre a abrangência do termo assistência humanizada, amplamente empregado pelos órgãos e profissionais de saúde ao tratarem dos Centros de Parto Normal. Este artigo, extraído de pesquisa anterior ${ }^{(6)}$, foi produzido com o objetivo de justificar a proposta de adequação de nova terminologia à assistência prestada a 
parturiente em Centro de Parto Normal. Sua finalidade é divulgar nossa proposta de mudança de terminologia, melhor adequando o conceito de assistência humanizada ao parto.

\section{JUSTIFICANDO APROPOSTA}

As presentes transformações no modelo assistencial direcionado à parturiente e a conseqüente valorização do trabalho da enfermeira obstétrica, nos Centros de Parto Normal, para a realização do parto e nascimento, remete-nos à importância de realçar o significado da relação entre assistência e Centro de Parto Normal.

As instituições deveriam propor-se a organizar os serviços de assistência obstétrica na perspectiva da promoção e da facilitação de um parto saudável, fisiológico e da prevenção de possíveis intervenções e agravos, inclusive aqueles resultantes da assistência, como a dor iatrogênica e a lesão genital da episiotomia desnecessária, entre outros ${ }^{(4)}$.

A literatura é rica em trabalhos voltados à assistência à mulher que vivencia o ciclo gravídico-puerperal e que, em sua totalidade, emprega o termo assistência humanizada. Por sua vez, existem autores que referem que para trabalhar com humanização é necessário despojar-se da onipotência própria da formação médica, trabalhando com uma equipe multiprofissional em que o espaço de cada um deve ser respeitado ${ }^{(7)}$.

$\mathrm{Na}$ assistência humanizada, demonstrar interesse e compromisso com o outro requer a conscientização dos possíveis dilemas éticos presentes nessa relação. Na proposta de relação humanizada, as informações a serem transmitidas aos clientes e deles recebidas são fundamentais ${ }^{(8)}$.

A humanização da assistência reside, também, nas relações interpessoais, em especial entre o profissional e o cliente e o acompanhante ${ }^{(9)}$.

O relacionamento entre paciente e profissional e instituição é fundamental para o processo de humanização, sendo este composto por fatores como comunicação, empatia, conhecimentos técnico-científicos e respeito pelos seres humanos ${ }^{(10)}$.

A humanização engloba uma série de diferentes aspectos referentes às idéias, aos valores e às práticas, envolvendo as relações entre os profissionais de saúde, os pacientes, os familiares e os acompanhantes, incluindo os procedimentos de rotina do serviço e a distribuição de responsabilidades dentro dessa equipe. No entanto, tais fatores tornam-se fragmentados se a experiência do nascimento não for reconhecida em seus aspectos emocionais ${ }^{(11)}$.

Ao prestar assistência humanizada à mulher, que vivencia o ciclo gravídico puerperal, os profissionais devem desenvolver habilidades relacionadas ao contato com essa mu- lher, favorecendo sua adequação emocional à gravidez e ao parto $^{(12)}$. Podem também ajudá-la a superar os medos, as ansiedades e as tensões. No modelo humanizado de atendimento, a parturiente e seu acompanhante devem ser recebidos pela equipe com empatia e respeito, considerando sempre suas opiniões, preferências e necessidades.

Acreditamos que a assistência humanizada está representada na expressão assistência centrada nas necessidades da cliente e vale ser aqui apresentada em maior profundidade. Não encontramos diferencial na assistência a que ambas de propõem, apenas cremos que a segunda apresenta maior amplitude para destacar a real assistência prestada e os elementos nela envolvidos.

Consideramos que a assistência obstétrica centrada nas necessidades da cliente deva ser baseada não apenas em procedimentos e normas técnicas pré-estabelecidas, mas na valorização da individualidade, visto que o ser humano é diferenciado pela própria natureza por ser racional e possuir características específicas, como caráter, personalidade, sentimentos, opiniões, crenças, desejos, aspirações, valores próprios, dignidade e senso de justiça, que devem ser respeitados, considerados e valorizados.

Ao assistir o indivíduo, o prestador do cuidado deve considerá-lo como um todo, com sua subjetividade e complexidade, sendo membro de um grupo familiar e de uma comunidade $^{(13)}$. Deve, ainda, identificar as mensagens enviadas pelo cliente/paciente e reconhecer seus códigos, compreendê-los e atuar de maneira a satisfazer as necessidades de atenção e de cuidado da clientela. Nesse processo de cuidar, não devem ser esquecidos o contexto de vida e os valores que o cliente traz quando de sua internação. Saber identificar as diferenças culturais e individuais contribui para a redução de desequilíbrios entre a assistência prestada e as necessidades básicas da cliente/paciente.

Nesse sentido, o cuidado deve ser oferecido de maneira holística, valorizando-se a pessoa que o recebe ${ }^{(14)}$. Portanto, a parturiente deve ser considerada como um ser biopsico-sócio-espiritual, para a qual a assistência de enfermagem deve atender as necessidades. Dentre outras, devemos destacar a promoção de sua adaptação ao ambiente institucional e a interação harmônica com o contexto onde recebe o cuidado - Centro de Parto Normal.

As necessidades humanas possuem diversos conceitos, porém nenhum deles é definitivo. Assim sendo, é possível estabelecer bases para futuras abordagens e reformulações. Essas necessidades são universais e classificam-se em nível psicobiológico, psicossocial e psicoespiritual, diferenciando-se apenas no modo de satisfazê-las para cada indivíduo. A assistência das necessidades humanas básicas consiste em um trabalho de equipe, que visa ao autocuidado, a recuperação, a manutenção e a promoção da saúde em colaboração com outros profissionais ${ }^{(15)}$. 
Como se vê, há estreita relação entre a filosofia de assistência que deve ser oferecida à mulher que vivencia o nascimento e o parto, e o Centro de Parto Normal. Julgamos oportuno, portanto, discorrer sobre a relação deste binômio Centro de Parto Normal - assistência centrada nas necessidades da parturiente.

\section{Discorrendo sobre assistência obstétrica centrada nas necessidades da parturiente}

Julgamos que o conceito de atenção obstétrica centrada nas necessidades da cliente melhor dimensiona o conceito de assistência humanizada, amplamente empregado, atualmente. Justificamos tal opção pelo seu caráter amplo que envolve um conjunto de conhecimentos, de práticas e de atitudes que visam não só a promoção do parto, mas também um nascimento saudável e a prevenção da morbimortalidade materna e perinatal, com início no pré-natal e garantia de que a equipe de saúde realiza procedimentos comprovadamente benéficos, para a mulher e para o recémnascido, que evite as intervenções desnecessárias, que preserve sua privacidade e autonomia, já que o nascimento é um evento fisiológico e mobilizador, considerado um dos fatos mais marcantes da vida ${ }^{(1)}$.

Existem autores que acreditam que as ações assistenciais para ser eficazes devem considerar não só as atividades técnicas, mas as expectativas da mulher.

Toda a equipe deve estar atenta no sentido de oferecer-lhe apoio, atenção e respeito de suas crenças e valores, seus medos, suas necessidades $^{(16)}$.

Conforme dito anteriormente, os textos com abordagem na assistência obstétrica prestada em Centros de Parto Normal reforçam o papel da humanização, porém, acreditamos que substituir esta expressão por assistência centrada nas necessidades da cliente mostrará a real abrangência da proposta de atenção desse novo modelo de assistência ao parto e nascimento.

Consideramos, outrossim, que a assistência obstétrica centrada nas necessidades da cliente caracteriza-se pelo direito à autonomia da parturiente, em que a informação é fator relevante, sendo a base principal para que tenha a liberdade de escolher ou recusar qualquer procedimento relacionado com seu próprio corpo, e que esta escolha seja pertinente e convergente ao seu bem-estar. Portanto, esta informação deve ser inteligível, exata, concisa, adaptada ao nível sociocultural e cognitivo de quem a recebe, para que o indivíduo possa ser capaz de, conscientemente, escolher qual a proposta para sua assistência que melhor se adapte, conforme seus princípios morais e éticos. Se não houver informação com qualidade, o direito de decidir adequadamente torna-se inexistente.
Vale esclarecer que, no Centro de Parto Normal, campo desse estudo, a parturiente e seu acompanhante são informados, constantemente, pela enfermeira obstétrica que os assiste, sobre a evolução do trabalho de parto e sobre eventuais mudanças de conduta para que possam colaborar durante todo o processo do trabalho de parto ativo até o nascimento. À cliente em trabalho de parto é permitido expressar seus sentimentos quanto aos procedimentos com os quais não concorda, cabendo à equipe, dentro de suas possibilidades, mudar a conduta de modo que a parturiente sinta-se segura em relação à assistência prestada.

Acreditamos também, que o empenho em manter o relacionamento entre os próprios profissionais e clientes, constitui-se parte da assistência obstétrica centrada nas necessidades da cliente, em que o respeito e a dignidade se tornem uma constante e sejam vistos como norma a ser praticada naturalmente.

Vale acrescentar que ainda há maternidades que não oferecem assistência obstétrica centrada nas necessidades da cliente, pois não priorizam a individualidade, a cultura e os costumes de cada mulher. Submetem-na, no momento da internação, a rotinas préestabelecidas pela organização, e na maioria das vezes retiram-lhe o direito à privacidade. Para evitar essa situação, a instituição deve preocupar-se com as necessidades da cliente como princípio da assistência de enfermagem definido em sua filosofia, oferecendolhe condições que, muitas vezes, são representadas por recursos humanos qualificados, por materiais e equipamentos e pela apropriada estrutura física do local ${ }^{(17)}$.

Para essa visão ampliada da assistência obstétrica, chamada de atenção humanizada, propomos sua substituição pela expressão assistência obstétrica centrada nas necessidades da cliente, considerada por nós de maior amplitude e pertinente à implantação e implementação de Centros de Parto Normal.

\section{Demonstrando a assistência obstétrica centrada nas necessidades da parturiente aplicada em Centro de Parto Normal}

Acreditamos ser oportuno citar que a assistência obstétrica centrada nas necessidades da parturiente é plenamente desenvolvida no Centro de Parto Normal de Itapecerica da Serra, SP, pois este segue os procedimentos definidos pelo orgão gestor máximo do país para a atenção à mulher durante o parto e o nascimento. Esta unidade, cujos partos são atendidos por enfermeiras obstétricas, realizou 10.559 partos normais no período compreendido entre janeiro de 2000 e janeiro de 2003. 
A seguir, destacamos os procedimentos adotados por esta unidade de atenção ao parto normal, os quais reforçam nossa certeza quanto à proposta de mudança de terminologia $^{(18)}$. No Centro de Parto Normal de Itapecerica da Serra, a parturiente conta com dieta livre, tem direito a um acompanhante de sua escolha, tem liberdade para movimentação durante o trabalho de parto, é estimulada à adoção de métodos não farmacológicos no alívio à dor - banho de aspersão e de imersão para relaxamento, massagens na região lombossacra, exercícios de respiração e de relaxamento, estímulos a movimentos corpóreos, tais como abaixar, levantar e balanço pélvico - o acompanhante é estimulado a participar na realização de massagens relaxantes para alívio da dor, são estimuladas as eliminações espontâneas (micção e evacuação). É a parturiente quem autoriza a realização do exame tocoginecológico, com respeito a sua privacidade. O profissional deve considerar o desejo de independência da parturiente no início do trabalho de parto e sua dependência no final deste, deve estimular a ingesta hídrica, realizar monitoramento fetal pela ausculta intermitente, usar o partograma, encorajar o parto em atmosfera favorável, permitir interação entre mãe e filho, estimular o contato pele a pele imediatamente após o nascimento, bem como o aleitamento precoce com estímulo à amamentação na primeira meia hora após o nascimento, estimular o vínculo afetivo com a secção do cordão umbilical pelo acompanhante, em condições estéreis, prevenir hipotermia do recém-nascido, favorecer a dequitação fisiológica com exame rotineiro da placenta e de membranas ovulares, permitir que a família fotografe o parto e o nascimento se desejar, autorizar alta precoce pós-parto para mãe e filho, com retorno ambulatorial após 48 horas, para consulta de ambos. Ao acompanhante é permitido o esclarecimento de dúvidas sobre condutas e procedimentos, bem como o estímulo à participação em todos os procedimentos durante o trabalho de parto e o parto.

\section{REFERÊNCIAS}

(1) Brasil. Ministério da Saúde. Federação Brasileira das Associações de Ginecologia e Obstetrícia. (FEBRASGO) / Associação Brasileira de Obstretrizes e Enfermeiros Obstetras (ABENFO). Parto, aborto e puerpério: assistência humanizada à mulher. Brasília; 2001.

(2) Organização Mundial de Saúde (OMS). Maternidade segura. Assistência ao parto normal: um guia prático. Brasília; 1996. (OMS/SRF/MSM).

(3) Costa Filho CF. Tratado de obstetrícia FEBRASGO. Rio de Janeiro: Revinter; 2000. Infecção puerperal. Cap. 28, p. 380.

(4) Diniz CSG. Entre a técnica e os direitos humanos: possibilidades e limites da humanização da assistência ao parto [tese]. São Paulo: Faculdade de Medicina da USP; 2001.
Com esta relação de condutas recomendadas pelo Ministério da Saúde, e definidas no protocolo de atendimento da unidade, acreditamos que conseguimos caracterizar a amplitude da assistência obstétrica prestada à mulher em Centros de Parto Normal, a qual, com base nos estudos anteriormente citados e em nossa experiência profissional, seria melhor caracterizada como assistência obstétrica centrada nas necessidades da parturiente.

\section{CONSIDERAÇÕES FINAIS}

Vale ressaltar que mesmo comprovado por evidências, o modelo assistencial empregado nos Centros de Parto Normal é gerador de resistências entre profissionais da área da saúde que têm dificuldade em admitir que a assistência obstétrica prestada nessa unidade é coerente com uma proposta de atenção integral à mulher em trabalho de parto.

Acreditamos que, por tratar-se de unidade com proposta inovadora, os Centros de Parto Normal em funcionamento, atualmente, no país, constituem-se em ricas experiências assistenciais e de ensino, tanto para os profissionais, quanto para os estudantes da área da saúde, mas em especial para as mulheres neles atendidas, pois podem usufruir de sua autonomia durante a atenção recebida. Cabe a nós, enfermeiras obstétricas que atuamos nessas unidades, divulgarmos nosso trabalho, favorecendo, portanto, a troca de experiências; assim, estaremos contribuindo para a disseminação da proposta deste modelo de assistência.

A dimensão dos fatores assistenciais, profissionais e institucionais que regem a filosofia dos Centros de Parto Normal reforçam nossa proposta de substituição da expressão assistência humanizada para assistência obstétrica centrada nas necessidades da parturiente.

(5) Osava RH. Assistência ao parto no Brasil o lugar dos nãomédicos [tese]. São Paulo: Faculdade de Saúde Pública da USP; 1997.

(6) Machado NXS. Infecção puerperal em um centro de parto normal: ocorrência e fatores de risco [dissertação]. São Paulo: Escola de Enfermagem da USP; 2004.

(7) Fabre ZL, Tobias L, Berreta IQ, Santiago ML. Humanização em UTI pediátrica: a equipe e a família. Arq Catarinenses Méd. 1992;21(1):34-7.

(8) Guimarães RL, Lunardi VL. O dilema ético frente à necessidade de revelação do diagnóstico de infecção hospitalar. Texto Contexto Enferm. 2000;9(2):137-46.

$\begin{array}{rrr}\text { Rev Esc Enferm USP } & \text { Centro de parto normal e a assistência obstétrica } \\ 2006 ; 40(2): 274-9 . & \text { centrada nas necessidades da parturiente } & \text { Machado } N X S, \text { Praça NS. }\end{array}$


(9) Basile ALO, Pinheiro MSB, Miyashita NT. Centro de parto normal: o futuro no presente. São Paulo: JICA; 2004.

(10) Malik AM. Humanização. Coren-SP. 2000;(29):2-5.

(11) Rattner D. Humanizando o nascimento e parto: o workshop. In: Síntese do $1^{\circ}$ Seminário Estadual Qualidade da Assistência ao Parto: contribuições da enfermagem; 1998 maio 14-15; Curitiba. Curitiba: ABEn - Seção PR; 1998. p. 24-5.

(12) Carneiro LM. Parto humanizado: humanizar é preciso. J Rede Saúde. 2000;(20):16-7.

(13) Cianciarullo TI. A avaliação do sistema de assistência de enfermagem como base do desenvolvimento do conhecimento na enfermagem. In: Cianciarullo TI, Gualda DMR, Melleiro MM, Anabuki MH. Sistema de assistência de enfermagem: evolução e tendências. São Paulo: Ícone; 2001. Cap. 16, p. 293-302.

(14) Souza MF. As teorias de enfermagem e sua influência nos processos cuidativos. In: Cianciarullo TI, Gualda DMR, Melleiro MM, Anabuki MH. Sistema de assistência de enfermagem: evolução e tendências. São Paulo: Ícone; 2001. Cap. 2, p. 29-39.
(15) Horta WA. O processo de enfermagem. São Paulo: EPU/Edusp; 1979. p. 33-4.

(16) Paschoal MLH, Rogenski NMB. Sistema de assistência de enfermagem perioperatória. In: Cianciarullo TI, Gualda DMR, Melleiro MM, Anabuki MH. Sistema de assistência de enfermagem: evolução e tendências. São Paulo: Ícone; 2001. Cap. 11, p. 201-19.

(17) Ceccato SR, Van der Sand ICP. O cuidado humano como princípio da assistência de enfermagem à parturiente e seus familiares. Rev Eletrôn Enferm. [on-line] 2001; 3(1) Disponível em: http://www.fen.ufg.br/revista.html. [Acesso em 19 mar. 2002].

(18) Hospital Geral de Itapecerica da Serra (SP). Protocolo de assistência humanizada ao parto e nascimento. Itapecerica da Serra: HGIS; 1999. 